\title{
Lifestyle intervention according to general recommendations improves glucose tolerance
}

Citation for published version (APA):

Mensink, M. R., Blaak, E. E., Corpeleijn, E., Saris, W. H. M., de Bruin, T. W. A., \& Feskens, E. (2003). Lifestyle intervention according to general recommendations improves glucose tolerance. Obesity Research, 11(12), 1588-1596. https://doi.org/10.1038/oby.2003.211

Document status and date:

Published: 01/01/2003

DOI:

10.1038/oby.2003.211

Document Version:

Publisher's PDF, also known as Version of record

\section{Please check the document version of this publication:}

- A submitted manuscript is the version of the article upon submission and before peer-review. There can be important differences between the submitted version and the official published version of record.

People interested in the research are advised to contact the author for the final version of the publication, or visit the DOI to the publisher's website.

- The final author version and the galley proof are versions of the publication after peer review.

- The final published version features the final layout of the paper including the volume, issue and page numbers.

Link to publication

\footnotetext{
General rights rights.

- You may freely distribute the URL identifying the publication in the public portal. please follow below link for the End User Agreement:

www.umlib.nl/taverne-license

Take down policy

If you believe that this document breaches copyright please contact us at:

repository@maastrichtuniversity.nl

providing details and we will investigate your claim.
}

Copyright and moral rights for the publications made accessible in the public portal are retained by the authors and/or other copyright owners and it is a condition of accessing publications that users recognise and abide by the legal requirements associated with these

- Users may download and print one copy of any publication from the public portal for the purpose of private study or research.

- You may not further distribute the material or use it for any profit-making activity or commercial gain

If the publication is distributed under the terms of Article $25 \mathrm{fa}$ of the Dutch Copyright Act, indicated by the "Taverne" license above, 


\title{
Lifestyle Intervention According to General Recommendations Improves Glucose Tolerance
}

\author{
Marco Mensink, * Ellen E. Blaak,* Eefje Corpeleijn,* Wim H. Saris, * Tjerk W. de Bruin, $\dagger$ and \\ Edith J. Feskens:
}

\begin{abstract}
MENSINK, MARCO, ELLEN E. BLAAK, EEFJE CORPELEIJN, WIM H. SARIS, TJERK W. DE BRUIN, AND EDITH J. FESKENS. Lifestyle intervention according to general recommendations improves glucose tolerance. Obes Res. 2003;11:1588-1596.

Objective: Changing dietary and physical activity habits has the potential to postpone or prevent the development of type 2 diabetes. However, it needs to be assessed whether moderate interventions, in agreement with current guidelines for the general population, are effective. We evaluated the impact of a 2-year combined diet and physical activity intervention program on glucose tolerance in Dutch subjects at increased risk for developing diabetes.
\end{abstract}

Research Methods and Procedures: Subjects with glucose intolerance were randomly assigned to either the lifestyle intervention group (INT) or control group (CON). The INT received regular dietary advice and was stimulated to increase their physical activity. The CON received a brief leaflet about healthy diet and increased physical activity. Primary outcome measure was the change in glucose tolerance.

Results: In total, 88 subjects completed 2 years of intervention (40 subjects in the INT, 48 subjects in the CON, mean BMI $29.4 \mathrm{~kg} / \mathrm{m}^{2}$ ). Subjects in the INT reduced their body weight, waist circumference, and (saturated) fat intake and improved their aerobic capacity. Two-hour plasma glucose concentration declined from 8.7 to $8.0 \mathrm{mM}$ in the INT and rose from 8.6 to $9.4 \mathrm{mM}$ in the $\mathrm{CON}(p<0.01)$. Subjects

Received for review April 28, 2003

Accepted in final form October 20, 2003.

*Department of Human Biology, Nutrition and Toxicology Research Institute, Maastricht University, Maastricht, The Netherlands; †Laboratory of Molecular Metabolism and Endocrinology, Department of Medicine, Maastricht University, Maastricht, The Netherlands; and \$Department of Nutrition and Health, National Institute for Public Health and the Environment, Bilthoven, The Netherlands.

Address correspondence to Marco Mensink, Department of Human Biology, Nutrition and Toxicology Research Institute Maastricht, Maastricht University, P.O. Box 616, 6200 MD Maastricht, The Netherlands.

E-mail: m.mensink@hb.unimaas.nl

Copyright $\odot 2003$ NAASO adherent to both the diet and exercise intervention showed the largest reduction in 2-hour glucose levels.

Discussion: Our results showed that a lifestyle intervention program according to general recommendations improves glucose tolerance, even in a less obese and more physical active population. Furthermore, our results underscore the importance of combining diet and physical activity to improve glucose tolerance and insulin resistance.

Key words: type 2 diabetes, diet, physical activity, impaired glucose tolerance, public health

\section{Introduction}

Impaired glucose tolerance (IGT) ${ }^{1}$ is considered to be a necessary stage en route to type 2 diabetes. The annual progression rate ranges from $4 \%$ to $8 \%$ in different populations $(1,2)$. Important factors predictive of the development of diabetes are obesity, dietary habits, and lack of physical activity (1-3). Therefore, changes in lifestyle should have the potential to postpone or prevent the development of type 2 diabetes in high-risk subjects, such as those with IGT.

Several studies have reported beneficial effects of lifestyle intervention programs in high-risk populations (4-7). Recently, two well-controlled clinical trials, the Finnish Diabetes Prevention Study (DPS) (6) and the U.S. Diabetes Prevention Program (DPP) (7), showed that changing dietary habits and increasing physical activity resulted in a risk reduction of almost $60 \%$ in the progression from IGT to type 2 diabetes after 3 years.

However, several issues remain. With regard to compliance and future implementation of such a prevention program, it needs to be assessed whether moderate interventions, in agreement with current guidelines for the general

\footnotetext{
${ }^{1}$ Nonstandard abbreviations: IGT, impaired glucose tolerance; DPS, Diabetes Prevention Study; DPP, Diabetes Prevention Program; OGTT, oral glucose-tolerance test; INT, intervention group; CON, control group; HOMA, homeostasis model assessment; $\mathrm{HbA}_{1 \mathrm{c}}$, glycated hemoglobin; energy\%, percentage of total energy intake; LDL, low-density lipoprotein; HDL, high-density lipoprotein.
} 
population, are effective. Intensive interventions, such as those sometimes used in aforementioned studies, are not likely to be adapted. In addition, it is imperative to know whether the results achieved by the DPS and DPP are valid for other populations, notably those with a different dietary and physical activity background. The level of physical activity in, for example, the Dutch population is relatively high. In 1997, slightly more than one-half of the population was, on average, moderately active for more than $0.5 \mathrm{~h} / \mathrm{d}$ (8), compared, for example, with about one-third of U.S. adults (9). Furthermore, the prevalence of obesity in the Dutch population is relatively low compared with other (European) populations (10).

Finally, lifestyle intervention programs are typically made up of a combination of dietary advice and exercise prescription. Both diet and physical activity are known to play an important role in the development of diabetes (1113). For a targeted implementation of lifestyle interventions into primary care, it is important to know whether a combination of diet and exercise is a more effective approach to prevent development of diabetes than diet or exercise alone.

Therefore, the aim of the present study is to evaluate the impact of a 2-year combined diet and physical activity intervention program, according to general recommendations, on glucose tolerance in Dutch subjects at increased risk for developing diabetes. In addition, we assessed whether adherence to the dietary intervention, to the physical activity intervention, or to both, is associated with a greater improvement in glucose tolerance.

\section{Research Methods and Procedures}

\section{Study Design}

The Study on Lifestyle Intervention and IGT, Maastricht, is designed to study whether a diet/physical activity intervention program can improve glucose tolerance in subjects with a high risk of developing type 2 diabetes. The rationale and the design for this study are discussed in more detail elsewhere (14).

Subjects with high risk of glucose intolerance, i.e., those of age $>40$ years and a family history of diabetes or a BMI $\geq 25 \mathrm{~kg} / \mathrm{m}^{2}$, were selected from an existing cohort (15) in the Maastricht area and invited to undergo a first oral glucose-tolerance test (OGTT). Those with known or overt diabetes were excluded.

Subjects with an elevated 2-hour blood glucose concentration were invited for a second OGTT. For definite inclusion in the study, mean 2-hour glucose concentration of both OGTTs had to be between 7.8 and $12.5 \mathrm{mM}$, together with a fasting glucose concentration $<7.8 \mathrm{mM}$. Furthermore, subjects were excluded according to the following criteria: previously diagnosed diabetes, other than gestational diabetes; medication use known to interfere with glucose tolerance; and participation in regular vigorous exercise or an intensive weight reduction program during the last year before the start of the study. Presence of any (chronic) disease that hampered participation in a lifestyle intervention program was a reason for exclusion, as was an improbability of a 5-year survival.

Eligible subjects were randomly assigned to the intervention group (INT) or control group (CON) by one of the staff members not involved in the intervention, with the use of a randomization list. Randomization was carried out with stratification for sex and mean 2-hour plasma glucose concentration. Dieticians, trainers, and staff members involved in the intervention had to be aware of the group assignment, but laboratory staff did not know subjects' group assignments. Power calculations indicated that 2 groups of 40 subjects would be sufficient to detect a $1 \mathrm{mM}$ difference in 2-hour glucose between groups after 2 years of intervention. The Medical Ethical Review Committee of Maastricht University approved the study protocol, and all subjects gave their written informed consent before the start of the study.

Primary outcome measure was a change in glucose tolerance, i.e., 2-hour blood glucose concentration during the OGTT. Secondary outcome measures were changes in fasting plasma glucose concentration, changes in insulin, insulin resistance [homeostasis model assessment (HOMA) index], glycated hemoglobin [hemoglobin $\mathrm{A}_{1 \mathrm{c}}\left(\mathrm{HbA}_{1 \mathrm{c}}\right)$ ], and body composition and aerobic capacity. Measurements were performed at baseline and after 1 and 2 years.

The intervention program consisted of a dietary and physical activity component, with visits scheduled at regular intervals throughout the study. The design of the intervention program is discussed in more detail elsewhere (14). Dietary recommendations were based on the Dutch guidelines for a healthy diet (Dutch Nutrition Council) and consisted of: carbohydrate intake of at least $55 \%$ of total energy intake (energy\%); total fat intake of $<30$ to 35 energy $\%$, with $<10$ energy $\%$ intake of saturated fatty acids; a cholesterol intake of $<33 \mathrm{mg} / \mathrm{MJ}$; and protein intake of 10 to 15 energy $\%$ and an intake of dietary fiber of at least $3 \mathrm{~g} / \mathrm{MJ}$. The goal was a body weight loss of $5 \%$ to $7 \%$, depending on the degree of obesity. Initially, this was achieved by stimulating people to change their daily dietary intake and to increase their physical activity according to the recommendations. If necessary, subjects received an example of a mild energy restricted diet during the 2 nd year. No low-energy diets (very-low-calorie diets) or dietary agents were given to achieve weight loss. Furthermore, participants were encouraged to stop smoking and, if necessary, to reduce alcohol intake. Dietary advice was given by a skilled dietitian on an individual basis after consideration of an individual 3-day food record. At the end of every session, goals were set for the next visit. The first visit was 4 to 6 weeks after randomization. Thereafter, every a visit was scheduled every 3 months. 
Subjects were encouraged to increase their physical activity to at least 30 minutes of moderate physical activity a day for at least 5 days a week (16). At the start of the study, individual advice was given about how to increase daily physical activity (walking, cycling, swimming), and goals were set. Furthermore, subjects were encouraged to participate in an exercise program, specially designed for this study, with components of aerobic exercise training and resistance training. Exercise sessions were supervised by trainers. Subjects had free access to these training sessions and were encouraged to participate at least $1 \mathrm{~h} / \mathrm{wk}$.

Subjects in the CON received oral and written information about the beneficial effects of a healthy diet, weight loss, and increased physical activity; however, no individual advice or programs were provided. No additional appointments were scheduled, apart from the visits for the annual measurements.

Two years' successful adherence to the dietary intervention was defined as reaching two or three of the following three dietary goals: total fat intake $<35$ energy $\%$, saturated fatty acid intake $<10$ energy $\%$, and fiber intake more than 3 g/MJ. Successful adherence to the physical activity intervention was defined as participation for at least $1 \mathrm{~h} / \mathrm{wk}$ in the supervised exercise sessions during the 2 years of intervention.

\section{Measurements}

To follow changes in glucose tolerance during the study, an OGTT was performed. Plasma glucose, plasma free fatty acid, and serum blood lipids were measured with a standard enzymatic technique automated on the Cobas Fara centrifugal analyzer. Low-density lipoprotein (LDL) cholesterol was calculated according to the formula of Friedewald (17). Plasma insulin concentration was measured with an enzyme-linked immunosorbent assay (Mercodia, Uppsala, Sweden) that shows no cross-reactivity with pro-insulin. $\mathrm{HbA}_{1 \mathrm{c}}$ was determined in a fasting serum sample with the high-performance liquid chromatography technique. (Reference value for our laboratory was $4.4 \%$ to $6.2 \%$.) The HOMA index for insulin resistance was calculated as described by Matthews et al. (18).

Body weight was measured with an electronic scale to the nearest $0.1 \mathrm{~kg}$, with the subject wearing light clothing only. Waist circumference (waist) was measured with the subject in standing position at the level midway between the lowest rib and the iliacal crest to the nearest $0.5 \mathrm{~cm}$, and hip circumference was measured as the maximum circumference over the buttocks to the nearest $0.5 \mathrm{~cm}$. An incremental exhaustive exercise test was performed on an electronically braked bicycle ergometer to determine the maximal power output and $\mathrm{VO}_{2 \max }$.

A 3-day food record (2 weekdays and 1 weekend day) was kept in the last 2 weeks before the annual visit. Food records were checked by a dietitian, and intake of nutrients
Table 1. Baseline characteristics

\begin{tabular}{llcc}
\hline & & Intervention & Control \\
\hline Subjects & $(\mathrm{M} / \mathrm{F})$ & $55(30 / 25)$ & $59(34 / 25)$ \\
$\quad$ Family history & $(\%)$ & 25.5 & 35.5 \\
Age & $($ years $)$ & $55.6 \pm 0.9$ & $57.8 \pm 1.0$ \\
Weight & $(\mathrm{kg})$ & $86 \pm 1.9$ & $83.7 \pm 1.5$ \\
BMI & $\left(\mathrm{kg} / \mathrm{m}^{2}\right)$ & $29.8 \pm 0.5$ & $29.3 \pm 0.4$ \\
$\quad$ BMI $<25 \mathrm{~kg} / \mathrm{m}^{2}$ & $(\%)$ & 7.3 & 8.5 \\
Waist & $(\mathrm{cm})$ & $102.4 \pm 1.5$ & $102.3 \pm 1.1$ \\
WHR & & $0.97 \pm 0.01$ & $0.97 \pm 0.01$ \\
Vo & & $2.15 \pm 0.1$ & $2.13 \pm 0.1$ \\
Fasting glucose & $(\mathrm{m} / \mathrm{min})$ & $5.9 \pm 0.1$ & $5.8 \pm 0.1$ \\
2-Hour glucose & $(\mathrm{mM})$ & $8.9 \pm 0.3$ & $8.6 \pm 0.2$ \\
HbA & & $5.9 \pm 0.1$ & $5.9 \pm 0.1$ \\
Fasting insulin & $(\%)$ & $13.8 \pm 1.3$ & $12.1 \pm 0.8$ \\
HOMA & & $3.8 \pm 0.4$ & $3.2 \pm 0.2$ \\
Cholesterol & $(\mathrm{mM})$ & $5.1 \pm 0.1$ & $5.2 \pm 0.1$ \\
HDL & $(\mathrm{mM})$ & $1.16 \pm 0.04$ & $1.10 \pm 0.03$ \\
LDL & $(\mathrm{mM})$ & $3.30 \pm 0.10$ & $3.44 \pm 0.10$ \\
Triglyceride & $(\mathrm{mM})$ & $1.59 \pm 0.18$ & $1.46 \pm 0.11$ \\
& & &
\end{tabular}

Data are mean $\pm \mathrm{SE} ; \mathrm{M} / \mathrm{F}$, male/female; WHR, waist-to-hip ratio.

was calculated with a validated computer program using the Dutch food composition table (NEVO, The Hague, The Netherlands).

\section{Statistical Analysis}

Data are presented as mean \pm SE. Differences between groups were tested with a Student's $t$ test for independent samples or by a $\chi^{2}$ test. Changes over time between groups were assessed with an ANOVA for repeated measures. Analysis of covariance was used for comparisons among multiple groups, with correction for differences in sex and baseline values. A $p$ value of $<0.05$ was considered statistically significant. Statistical analysis were performed with Statview 5.0 for Macintosh (SAS Institute, Cary, NC).

\section{Results}

Screening people for eligibility was begun in March 1999. The first study subject was randomized in June 1999, and the last was randomized in May 2000. (For details of the screening, see Ref. 14.) Follow-up after 2 years of intervention was completed in June 2002. In total, 114 subjects were randomized, 55 to the INT and 59 to the CON. No differences were seen in baseline characteristics between groups (see Table 1). Fourteen subjects in the INT and eight subjects in the CON discontinued the study. In five cases, a 
Table 2. Changes in dietary intake

\begin{tabular}{|c|c|c|c|c|c|c|}
\hline \multirow[b]{2}{*}{ Group } & \multirow[b]{2}{*}{ Baseline } & \multirow[b]{2}{*}{ Year 1} & \multirow[b]{2}{*}{ Year 2} & \multicolumn{3}{|c|}{ ANOVA } \\
\hline & & & & Group & Time & Interaction \\
\hline \multicolumn{7}{|c|}{ Energy intake (MJ) } \\
\hline INT & $8.88 \pm 0.39$ & $8.10 \pm 0.35$ & $7.94 \pm 0.35$ & NS & $<0.01$ & 0.13 \\
\hline $\mathrm{CON}$ & $8.54 \pm 0.33$ & $8.45 \pm 0.34$ & $8.28 \pm 0.38$ & & & \\
\hline \multicolumn{7}{|c|}{ Carbohydrates (En\%) } \\
\hline INT & $41.9 \pm 1.1$ & $47.0 \pm 1.3$ & $47.4 \pm 0.9$ & 0.06 & $<0.01$ & $<0.01$ \\
\hline $\mathrm{CON}$ & $42.9 \pm 1.0$ & $42.9 \pm 1.1$ & $43.7 \pm 0.9$ & & & \\
\hline \multicolumn{7}{|l|}{ Fat $(\operatorname{En} \%)$} \\
\hline INT & $36.6 \pm 1.0$ & $31.1 \pm 1.1$ & $31.8 \pm 0.8$ & $<0.01$ & $<0.01$ & $<0.01$ \\
\hline $\mathrm{CON}$ & $35.9 \pm 1.0$ & $35.4 \pm 0.9$ & $35.6 \pm 0.6$ & & & \\
\hline \multicolumn{7}{|l|}{ SAFA $(\operatorname{En} \%)$} \\
\hline INT & $14.2 \pm 0.4$ & $11.1 \pm 0.5$ & $11.1 \pm 0.4$ & $<0.01$ & $<0.01$ & $<0.01$ \\
\hline $\mathrm{CON}$ & $14.1 \pm 0.5$ & $13.6 \pm 0.5$ & $14.1 \pm 0.3$ & & & \\
\hline \multicolumn{7}{|c|}{ Cholesterol (mg/MJ) } \\
\hline INT & $26.6 \pm 1.6$ & $22.4 \pm 1.2$ & $22.5 \pm 1.1$ & 0.10 & $<0.01$ & NS \\
\hline $\mathrm{CON}$ & $27.6 \pm 1.7$ & $26.9 \pm 1.5$ & $26.0 \pm 1.8$ & & & \\
\hline \multicolumn{7}{|l|}{ Protein $(\mathrm{En} \%)$} \\
\hline INT & $15.9 \pm 0.5$ & $17.7 \pm 0.5$ & $17.5 \pm 0.4$ & $<0.05$ & $<0.05$ & 0.07 \\
\hline $\mathrm{CON}$ & $15.8 \pm 0.4$ & $16.3 \pm 0.6$ & $16.1 \pm 0.4$ & & & \\
\hline \multicolumn{7}{|l|}{ Fiber $(\mathrm{g} / \mathrm{MJ})$} \\
\hline INT & $2.8 \pm 0.1$ & $3.3 \pm 0.2$ & $3.1 \pm 0.1$ & $<0.01$ & $<0.01$ & 0.07 \\
\hline $\mathrm{CON}$ & $2.6 \pm 0.1$ & $2.7 \pm 0.1$ & $2.7 \pm 0.1$ & & & \\
\hline
\end{tabular}

Data are mean \pm SE. En\%, energy\%; SAFA, saturated fatty acids.

medical reason was given, and in 17 cases, subjects refused to attend the annual visits (11 INT, $6 \mathrm{CON})$. Another four participants had incomplete data after 2 years (1 INT, 3 CON). No differences were seen in age, gender, initial BMI, or baseline fasting and 2-hour plasma glucose concentration between participants and dropouts (data not shown). No serious adverse events were observed in the INT during the 2 years of follow-up. Analysis after 2 years of intervention included only those subjects still participating in the study after 2 years: 40 INT subjects and 48 CON subjects.

Results of the dietary intervention are presented in Table 2. Energy intake gradually decreased over time in both groups, but it was more pronounced in the INT. However, change over time was not statistically significant different between groups $(p=0.13$ ). Subjects in the INT successfully increased their intake of carbohydrates and reduced their intake of total fatty acids and saturated fatty acids, whereas no changes in dietary habits were seen in the CON ( $p<$ 0.01 for difference in change over time between groups). Furthermore, fiber intake was increased in the INT after 1 and 2 years, compared with no change in the CON ( $p=$ 0.07 for change over time between groups).
Table 3 shows the changes in characteristics after 1 and 2 years of intervention $(n=88)$. Significant differences between the INT and CON after 1 and 2 years were found for changes in body weight, BMI, saggital abdominal diameter, and aerobic capacity (Table 2). Mean weight loss in the INT was $-3.1 \pm 0.6 \mathrm{~kg}$ after 1 year and $-2.4 \pm 0.7 \mathrm{~kg}$ after 2 years, compared with a weight change of $-0.2 \pm 0.5 \mathrm{~kg}$ and $-0.1 \pm 0.5 \mathrm{~kg}$ in the CON after 1 and 2 years, respectively. Changes between groups in percentage body fat, waist circumference, fasting insulin, and HOMA index were significantly different after 1 year, but changes were no longer statistically significantly different after 2 years of intervention. Importantly, 2-hour plasma glucose concentration declined in the INT and increased in the CON: from $8.7 \pm 0.3$ $\mathrm{mM}$ at baseline to $8.0 \pm 0.4 \mathrm{mM}$ after 2 year in the INT (mean change $-0.6 \pm 0.3 \mathrm{mM}$ ), compared with an increase from $8.6 \pm 0.3 \mathrm{mM}$ at baseline to $9.4 \pm 0.4 \mathrm{mM}$ after 2 years in the CON (mean change $+0.8 \pm 0.4 \mathrm{mM}$ ) (see Table 3 and Figure 1). Normal glucose tolerance was present in $50 \%$ of the subjects in the INT (20/40) after 2 years compared with $29 \%$ in the CON $(16 / 48 ; p<0.05)$. Serum triacylglycerol decreased during the study in the INT 
Table 3. Change in characteristics of the study population after 1 and 2 years of intervention $(n=88,40$ INT/48 $\mathrm{CON})$

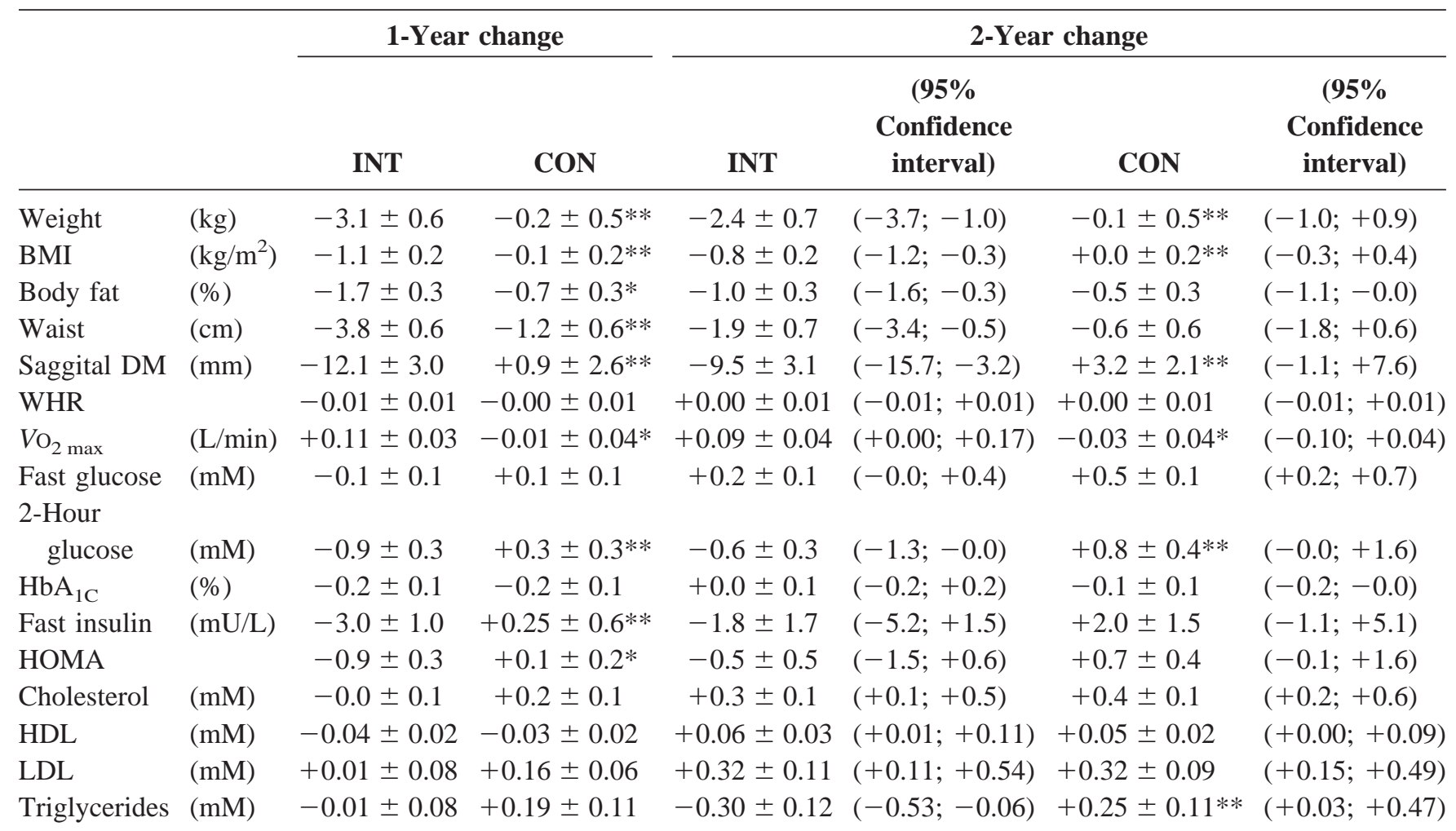

Data are mean \pm SE (95\% confidence interval). WHR, waist-to-hip ratio; DM, diameter.

$* p$ value $<0.05$ between groups.

$* * p$ value $<0.01$ between groups.

compared with an increase among $\mathrm{CON}$, with a significant difference in change after 2 years. No differences between INT and CON were observed in total, high-density lipoprotein (HDL) and LDL cholesterol, although a slight increase was observed over time in both groups.

To assess the separate or combined effects of diet and exercise, the changes in several variables were compared among subjects fully compliant to the dietary intervention ( $n=10)$, exercise intervention $(n=9)$, both diet and exercise intervention $(n=10)$, and neither diet nor exercise ( $n=11$ ) (for criteria, see "Research Methods and Procedures"). As shown in Figure 2, the combination of diet and exercise resulted in a significantly larger weight loss $(-6.2 \pm 1.6 \mathrm{~kg})$ and larger reduction in waist circumference $(-5.7 \pm 2.0 \mathrm{~cm})$ after 2 years compared with the other subgroups (see Figure 2). Changes in fasting insulin were greatest in the group compliant to diet and exercise. Also, changes in 2-hour plasma glucose were more pronounced in the diet and exercise group (mean change in 2-hour glucose $-1.9 \pm 0.6 \mathrm{mM}$; ANOVA: $p=0.09$ ).

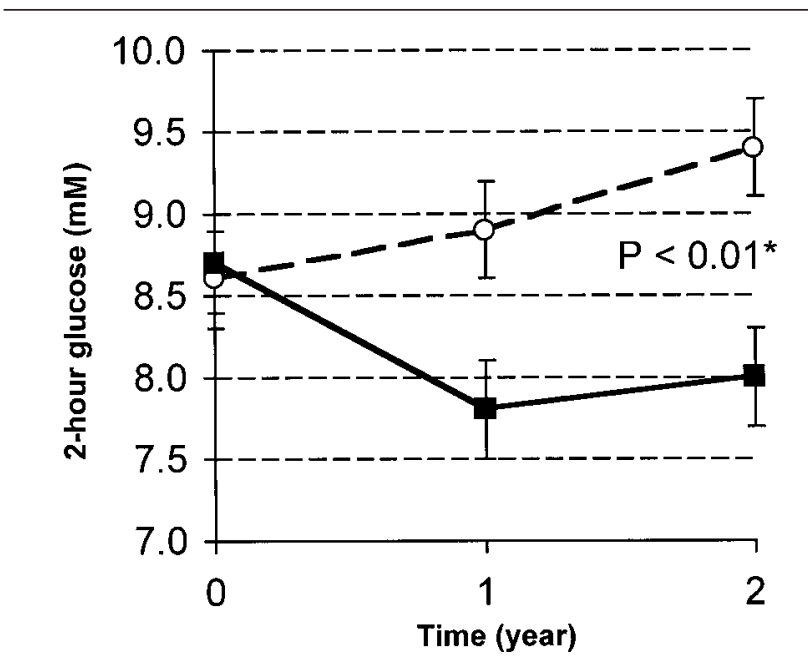

Figure 1: Two-hour plasma glucose concentration for INT ( $\longrightarrow$ ) and $\operatorname{CON}(\bigcirc,---$ - ) at baseline and after 1 and 2 years of follow-up. Data are means $\pm \mathrm{SE}$. $*, p<0.01$. ANOVA repeated measures for time $\mathrm{x}$ group interaction. 
A

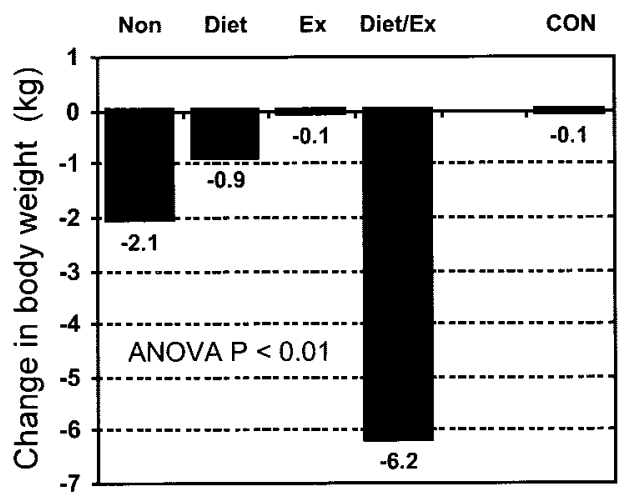

C

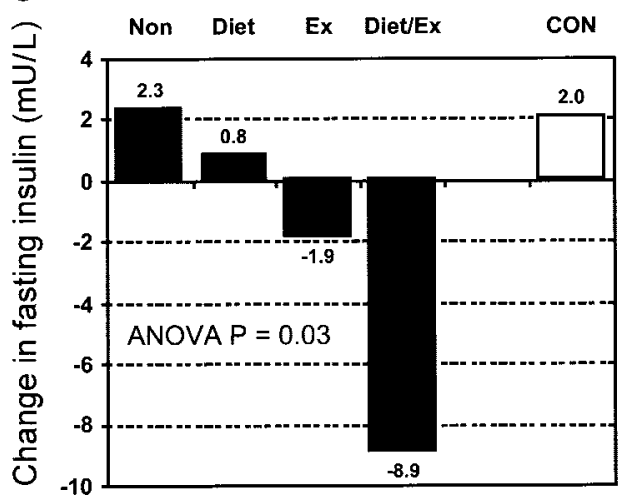

B

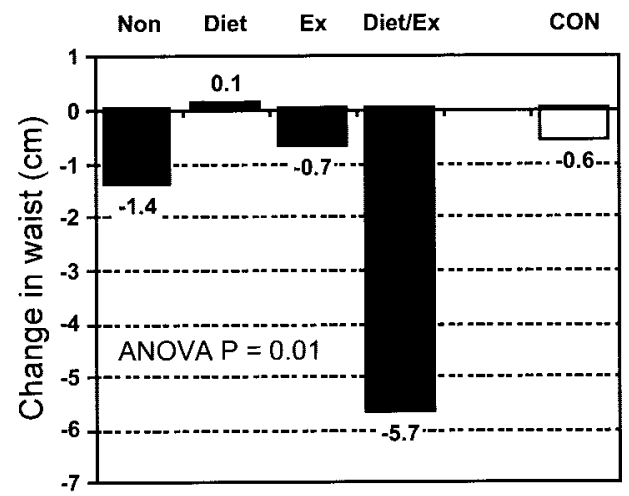

D

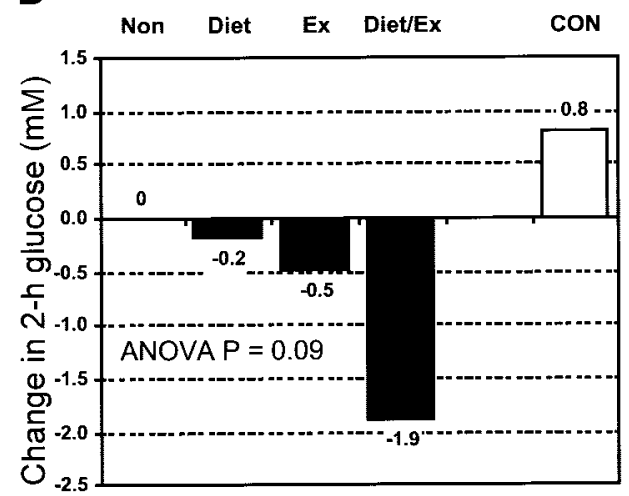

Figure 2: Mean changes after 2 years of follow-up in body weight (A), waist circumference (B), fasting insulin (C), and 2-hour glucose (D) in subjects in the INT fully compliant to the dietary program (Diet), exercise program (Ex), diet and exercise (Diet/Ex), or neither (Non). As a reference group, change in the CON is given (open bars). ANOVA, ANOVA among four INT subgroups.

\section{Discussion}

The present study showed that a combined dietary and physical activity intervention program, according to general recommendations, improved glucose tolerance in a population at risk for developing type 2 diabetes. After 2 years, postload blood glucose concentration was reduced from 8.7 to $8.0 \mathrm{mM}$ in the INT, compared with an increase from 8.6 to $9.4 \mathrm{mM}$ in the CON. This indicates that the risk of developing type 2 diabetes is reduced. Interestingly, subjects adherent to both the diet and exercise intervention showed the largest reduction in 2-hour blood glucose concentration and fasting insulin concentration and the largest reduction in body weight and waist circumference, indicating that the combination of diet and exercise is most effective in improving the metabolic profile.

The intervention strategy we used in this randomized trial was based on general public health recommendations. The dietary intervention program was designed according to guidelines from the Dutch Nutrition Council and was not supported by (very) low-energy diets or other dieting agents. Furthermore, low- to moderate-intensity physical activity for $30 \mathrm{~min} / \mathrm{d}$ was prescribed, instead of high-inten- sity exercise. Such a regimen, based on general recommendations, is much more suitable for preventing diabetes because it is less time consuming and much better tolerated than very intensive intervention programs. This is important considering the fact that most subjects at increased risk for developing diabetes are middle-aged and are more-or-less obese.

In the last decade, several studies have shown the efficacy of lifestyle intervention programs in reducing the incidence of type 2 diabetes (4-7). The Finnish DPS (6) and the U.S. DPP (7) reported, after a mean follow-up of 3 years, a risk reduction of 58\% in the dietary and physical activity INT. Consistent with these reports, our findings clearly show the impact of changes in diet and physical activity on glucose tolerance. Our observed reduction in 2-hour blood glucose of $0.9 \mathrm{mM}$ after 1 year in the present study is comparable with the reduction after 1 year reported in the interim paper of the DPS (19). The Dutch population has a low prevalence of obesity compared with other (European) populations (10). Our study population was less obese (mean BMI 29.4 $\mathrm{kg} / \mathrm{m}^{2}$ ) compared with the Finnish (BMI $31 \mathrm{~kg} / \mathrm{m}^{2}$ ) and the American (mean BMI $34 \mathrm{~kg} / \mathrm{m}^{2}$ ) study population. Further- 
more Dutch subjects are known for their relatively high level of physical activity. Thus, our results indicate that a modest lifestyle intervention program is effective in a less obese, more active population and leads to a comparable improvement in glucose tolerance.

Besides the lifestyle approach, several studies have investigated the effect of early drug interventions to prevent or delay the conversion from IGT to type 2 diabetes. The Study to Prevent Non-insulin-dependent Diabetes Mellitus (STOP-NIDDM) trial showed that acarbose, an $\alpha$-glucosidase inhibitor, reduced the risk of diabetes by $25 \%$ after 3.3 years (20). Metformin, a biguanide, reduced the risk of diabetes substantially in the American DPP (31\%), although the lifestyle intervention was much more effective (58\%) (7). Thus, although drug intervention reduces the incidence of diabetes, lifestyle changes reduce the incidence to a much larger extent.

Our lifestyle intervention program not only improved glucose tolerance but also successfully reduced (abdominal) adiposity (body weight and waist circumference) and improved aerobic fitness $\left(V_{2 \max }\right)$. Furthermore, serum triacylglycerol was reduced in the INT. Results of a metaanalysis of prospective studies showed that for each millimole per liter triacylglycerol increase, the risk for cardiovascular disease increases $14 \%$ for men and $37 \%$ for women, independently of HDL cholesterol (21). Fasting triacylglycerol is also a risk factor for the development of type 2 diabetes (22).

Beside being a risk factor for the progression to type 2 diabetes, the 2-hour blood glucose concentration is also considered an independent risk factor for cardiovascular disease (23). A metaregression analysis of 20 studies concluded that nondiabetic degrees of fasting and postprandial hyperglycemia were associated with cardiovascular disease (24). Thus, the decrease in 2-hour plasma glucose after 2 years of intervention indicates not only a reduced diabetes risk but also a lower risk for cardiovascular disease.

What determines the success of a lifestyle intervention program? Is it predominantly the dietary intervention, the physical activity part, or the combination of both? Only a few studies have addressed this question. The Oslo Diet and Exercise Study concluded that the combination of diet and exercise was most effective (25), whereas the Chinese Da Qing IGT and Diabetes Study observed no additional benefit of combining diet and exercise because diet or exercise alone was equally effective (5). In our study, after 2 years, subjects in the INT were divided into four different groups based on reaching intervention goals for diet and exercise. Subjects adherent to both diet and exercise showed the highest improvement in glucose tolerance, i.e., $-1.9 \mathrm{mM}$ reduction in 2-hour glucose after 2 years, which is considerably higher than the $-0.8 \mathrm{mM}$ reduction in 2-hour glucose observed for the INT as a whole and would, in theory, convert the IGT status to normal. This would suggest that the combination of diet and exercise is more effective than diet or exercise alone. However, caution should be taken when drawing definite conclusions from these data because the groups were defined afterwards and not beforehand. Subjects adherent to the dietary and exercise intervention may have been the most motivated individuals and, therefore, most willing to change their lifestyle habits, resulting in the largest improvements. Nevertheless, these data do indicate that a lifestyle intervention based on general recommendations, when strictly followed (i.e., including those subjects adherent to both the dietary and the physical activity interventions), results in much larger changes in body weight and glucose tolerance than when considered in the INT as a whole.

What explains the beneficial effect of lifestyle changes on glucose tolerance? A considerably larger reduction in body weight and waist circumference was observed in those adherent to both diet and exercise. This increased (abdominal) weight loss is probably an important mediator of the improved glucose tolerance. Adding physical exercise to a (diet-induced) weight loss program is important because it improves weight maintenance in the long term (26). Apart from this, acute exercise and exercise training enhance insulin-stimulated GLUT4 translocation and result in an improved glucose uptake by muscle (27). Furthermore, exercise training improves the ability to oxidize fatty acids in skeletal muscle (28). This is important because the insulinresistant state is characterized by an impaired capacity to oxidize fatty acids $(29,30)$, which could play an important role in the development of type 2 diabetes (31). The increased maximal oxygen consumption in the INT, as compared with the CON, reflects the better aerobic capacity due to physical training. Changes in dietary intake could also explain the improved glucose tolerance, in a direct manner and through concomitant weight loss. Both a reduction in total fat intake and a substitution of unsaturated fatty acids for saturated fatty acids improve insulin sensitivity (11). Additionally, an increased fiber intake is inversely associated with the risk of diabetes (12). All together, several mechanisms, each acting on distinct aspects of insulin resistance, can explain the beneficial effect of a combined diet and physical activity intervention program on glucose tolerance.

The present findings clearly show the impact of lifestyle changes on glucose tolerance in a Dutch population at increased risk for diabetes. It shows that a moderate lifestyle intervention program according to general public health recommendations is effective in a population with a relatively low obesity rate and a relatively high level of physical activity. Furthermore, our results underscore the importance of combining diet and physical activity to improve glucose tolerance. Awareness of the impact of early lifestyle interventions in those at increased risk for diabetes should 
be raised to enable development of strategies to reduce the burden of type 2 diabetes.

\section{Acknowledgments}

We thank Jos Stegen for his support during the numerous OGTTs and the analytical measurements. Furthermore, we thank Tanja Hermans-Limpens, Ilse Nijs, and Marja van der Hulst for their help with the dietary intervention and their efforts to motivate the subjects to participate. This work was supported by a grant from the Dutch Diabetes Research Foundation (DFN 98.901) and by a grant from the Netherlands Organization for Scientific Research (ZonMW 94035-034).

\section{References}

1. Edelstein SL, Knowler WC, Bain RP, et al. Predictors of progression from impaired glucose tolerance to NIDDM: an analysis of six prospective studies. Diabetes. 1997;4:701-10.

2. de Vegt F, Dekker JM, Jager A, et al. Relation of impaired fasting and postload glucose with incident type 2 diabetes in a Dutch population: the Hoorn Study. JAMA. 2001;16:2109-13.

3. Hu FB, Manson JE, Stampfer MJ, et al. Diet, lifestyle, and the risk of type 2 diabetes mellitus in women. $N$ Engl J Med. 2001;11:790-7.

4. Eriksson KF, Lindgarde F. Prevention of type 2 (non-insulin-dependent) diabetes mellitus by diet and physical exercise: the 6-year Malmo feasibility study. Diabetologia. 1991;12: 891-8.

5. Pan XR, Li GW, Hu YH, et al. Effects of diet and exercise in preventing NIDDM in people with impaired glucose tolerance: the Da Qing IGT and Diabetes Study. Diabetes Care. 1997;4:537-44.

6. Tuomilehto J, Lindstrom J, Eriksson JG, et al. Prevention of type 2 diabetes mellitus by changes in lifestyle among subjects with impaired glucose tolerance. $N$ Engl $\mathrm{J}$ Med. 2001;18:1343-50.

7. Knowler WC, Barrett-Connor E, Fowler SE, et al. Reduction in the incidence of type 2 diabetes with lifestyle intervention or metformin. $N$ Engl J Med. 2002;6:393-403.

8. Schuit AJ, Feskens EJ, Seidell JC. Physical activity in relation to sociodemographic variables and health status of adult men and women in Amsterdam, Doetinchen and Maastricht. Ned Tijdschr Geneeskd. 1999;30:1559-64.

9. Jones DA, Ainsworth BE, Croft JB, Macera CA, Lloyd EE, Yusuf HR. Moderate leisure-time physical activity: who is meeting the public health recommendations? A national cross-sectional study. Arch Fam Med. 1998;3:285-9.

10. Visscher TL, Kromhout D, Seidell JC. Long-term and recent time trends in the prevalence of obesity among Dutch men and women. Int J Obes Relat Metab Disord. 2002;9: $1218-24$.

11. Vessby B, Unsitupa M, Hermansen K, et al. Substituting dietary saturated for monounsaturated fat impairs insulin sensitivity in healthy men and women: the KANWU Study. Diabetologia. 2001;3:312-9.
12. Salmeron J, Manson JE, Stampfer MJ, Colditz GA, Wing AL, Willett WC. Dietary fiber, glycemic load, and risk of non-insulin-dependent diabetes mellitus in women. JAMA. 1997;6:472-7.

13. Hu FB, Sigal RJ, Rich-Edwards JW, et al. Walking compared with vigorous physical activity and risk of type 2 diabetes in women: a prospective study. JAMA. 1999;15:1433-9.

14. Mensink M, Corpeleijn E, Feskens EJ, et al. Study on lifestyle-intervention and impaired glucose tolerance Maastricht (SLIM): design and screening results. Diabetes Res Clin Pract. 2003;1:49-58

15. van Dam RM, Boer JM, Feskens EJ, Seidell JC. Parental history of diabetes modifies the association between abdominal adiposity and hyperglycemia. Diabetes Care. 2001;8: 1454-9.

16. American College of Sports Medicine Position Stand. The recommended quantity and quality of exercise for developing and maintaining cardiorespiratory and muscular fitness, and flexibility in healthy adults. Med Sci Sports Exerc. 1998;6: 975-91.

17. Friedewald WT, Levy RI, Fredrickson DS. Estimation of the concentration of low-density lipoprotein cholesterol in plasma, without use of the preparative ultracentrifuge. Clin Chem. 1972;6:499-502.

18. Matthews DR, Hosker JP, Rudenski AS, Naylor BA, Treacher DF, Turner RC. Homeostasis model assessment: insulin resistance and beta-cell function from fasting plasma glucose and insulin concentrations in man. Diabetologia. 1985;7:412-9.

19. Eriksson J, Lindstrom J, Valle T, et al. Prevention of type II diabetes in subjects with impaired glucose tolerance: the Diabetes Prevention Study (DPS) in Finland: study design and 1-year interim report on the feasibility of the lifestyle intervention programme. Diabetologia. 1999;7:793-801.

20. Chiasson JL, Josse RG, Gomis R, Hanefeld M, Karasik A, Laakso M. Acarbose for prevention of type 2 diabetes mellitus: the STOP-NIDDM randomised trial. Lancet. 2002;9323: 2072-7.

21. Hokanson JE, Austin MA. Plasma triglyceride level is a risk factor for cardiovascular disease independent of high-density lipoprotein cholesterol level: a meta- analysis of populationbased prospective studies. J Cardiovasc Risk. 1996;2:213-9.

22. Lee ET, Welty TK, Cowan LD, et al. Incidence of diabetes in American Indians of three geographic areas: the Strong Heart Study. Diabetes Care. 2002;1:49-54.

23. Laakso M. Hyperglycemia and cardiovascular disease in type 2 diabetes. Diabetes. 1999;5:937-42.

24. Coutinho M, Gerstein HC, Wang Y, Yusuf S. The relationship between glucose and incident cardiovascular events: a metaregression analysis of published data from 20 studies of 95,783 individuals followed for 12.4 years. Diabetes Care. 1999;2:233-40.

25. Torjesen PA, Birkeland KI, Anderssen SA, Hjermann I, Holme I, Urdal P. Lifestyle changes may reverse development of the insulin resistance syndrome: the Oslo Diet and Exercise Study: a randomized trial. Diabetes Care. 1997;1: $26-31$. 
26. Tremblay A, Doucet E, Imbeault P. Physical activity and weight maintenance. Int J Obes Relat Metab Disord. 1999; S50-4.

27. Borghouts LB, Keizer HA. Exercise and insulin sensitivity: a review. Int J Sports Med. 2000;1:1-12.

28. Jeukendrup AE, Saris WH, Wagenmakers AJ. Fat metabolism during exercise: a review, part II: regulation of metabolism and the effects of training. Int J Sports Med. 1998;5: 293-302.

29. Blaak EE, Wagenmakers AJ, Glatz JF, et al. Plasma FFA utilization and fatty acid-binding protein content are diminished in type 2 diabetic muscle. Am J Physiol Endocrinol Metab. 2000;1:E146-54.

30. Mensink M, Blaak EE, van Baak MA, Wagenmakers AJ, Saris WH. Plasma free fatty acid uptake and oxidation are already diminished in subjects at high risk for developing type 2 diabetes. Diabetes. 2001;11:2548-54.

31. McGarry JD. Banting lecture 2001: dysregulation of fatty acid metabolism in the etiology of type 2 diabetes. Diabetes. 2002;1:7-18. 